\title{
Abelardo Gamarra "E1 Tunante" y el narrador forastero en los artículos de costumbres en “Rasgos de Pluma” (1875-1877)
}

\section{Abelardo Gamarra "E1 Tunante" and the narrator serrano in costumbrist articles in "Rasgos de Pluma" (1875-1877)}

Jannet Torres Espinoza ${ }^{2}$

\section{Resumen:}

Abelardo Gamarra construyó en sus artículos de costumbres un narrador costumbrista con características de un forastero serrano en Lima. En esta construcción, influyen algunas señas biográficas del escritor, así como el contexto de migraciones del campo a Lima a mediados del XIX. Analizo tres constantes relacionadas en sus artículos: el significado del seudónimo "El Tunante", la crítica a Lima y la nostalgia que expresa el narrador por la sierra. El presente estudio gira en torno de

1 El presente estudio es parte de mi tesis de maestría (en proceso de elaboración), en la cual investigo la representación de la migración interna en los artículos de costumbres de Abelardo Gamarra.

2 Licenciada en literatura por la Universidad Nacional Mayor de San Marcos. Candidata a Magíster en Literatura Peruana y Latinoamericana por la mencionada casa de estudios.

Contacto: jan85.jt@gmail.com 
cuatro artículos publicados en su columna "Rasgos de pluma" en el diario peruano El Nacional entre 1875 y 1877.

Palabras clave: artículo de costumbres, "El Tunante", narrador costumbrista, forastero, Lima

\section{Abstract:}

Abelardo Gamarra presented in his costumbrist articles a costumbrist narrator with distinctive serrano features of an outsider in Lima. Different aspects of his biography as a writer and the context of migrations from the Andean countryside to Lima in the middle of the XIX are an important aspect of this article. I analyze three related motifs in his articles: the meaning of the pseudonym "El Tunante", the criticisim to Lima and the narrator's nostalgia for the life in the Andes. For the present study I have selected four articles published in his column "Rasgos de Pluma" in the Peruvian newspaper El Nacional between 1875 and 1877.

Keywords: costumbrist article, "El Tunante", costumbrist narrator, outsider, Lima

$$
* * *
$$

\section{Introducción}

164 Abelardo Gamarra fue un popular y prolífico escritor en la segunda mitad del siglo XIX. Fue contemporáneo de Manuel González Prada, Clorinda Mato de Turner, Mercedes Cabello, Manuel Moncloa y Covarrubias y otros que empezaron a publicar en la década de 1870 y continuaron publicando durante la posguerra. Entre estos personajes, Abelardo Gamarra logró distinguir su pluma desde 1871, con mayor visibilidad desde 1875 cuando obtuvo su columna semanal "Rasgos de pluma" 
(El Nacional. Lima, Perú. 1875 a 1880 /1885 a 1889) donde publicaba artículos de costumbres bajo el seudónimo de "El Tunante". Aunque los lectores sabían que tras la firma se encontraba Gamarra, el seudónimo no resultaba intercambiable con el nombre del sujeto real. "El Tunante" más que un seudónimo es una entidad textual con la que lo identificaron sus lectores a lo largo de los once años de su columna.

En el presente estudio, propongo que Abelardo Gamarra construye a "El Tunante" como un narrador forastero serrano en Lima. La configuración de este narrador se logra a través de cualidades que se exponen en su columna "Rasgos de pluma”. Desarrollo mi propuesta en tres apartados. En el primero, presento algunos datos biográficos de Gamarra en diálogo con la migración interna de sierra a costa en la segunda mitad del siglo XIX. En el segundo apartado, llevo a cabo el análisis del seudónimo "El Tunante" que se ilustra con cualidades presentes en sus artículos. En el tercero, visibilizo el complejo vínculo de "El Tunante" con Lima, entre la expectativa por la capital y la nostalgia por el terruño de procedencia.

Para los fines de este trabajo, he delimitado cronológicamente en los primeros años de publicaciones en "Rasgos de Pluma", entre 1875 y 1877, antes de la guerra del Pacífico. De este tramo, he seleccionado cuatro artículos de costumbres representativos en los que es explícita la presencia del narrador. Esta delimitación cronológica responde sobre todo al hecho de que a partir de la guerra, "El Tunante" además de ser un forastero serrano suma otras cualidades de posguerra, como señala Fernández ${ }^{3}$, características que son objeto de otro estudio.

3 Justo Fernández refiere dos etapas en la obra de Gamarra: antes de la Guerra del Pacífico, y un segundo momento a partir de dicho aconte- 


\section{Abelardo Gamarra y la migración a mediados del XIX}

El narrador en el artículo de costumbres suele estar vinculado a la imagen del escritor real de acuerdo con un pacto de verosimilitud, distinto al pacto ficcional en otros tipos textuales literarios convencionales contemporáneos. El narrador costumbrista se configura como participante de la realidad que comenta; para lograrlo, recurre a experiencias reales del autor y se dirige al lector bajo referentes inmediatos compartidos. Por ello, mi análisis de "El Tunante", narrador forastero, va acompañado de algunos datos biográficos del autor y apuntes sobre la migración de la sierra a la costa en la segunda mitad del XIX. ${ }^{4}$

De acuerdo con sus biógrafos, Abelardo Gamarra nació entre 1850 y 1860, en Sarín, distrito de Huamachuco (Trujillo). ${ }^{5}$

cimiento bélico. La diferencia entre ambas etapas es una cuota de pesimismo en el segundo momento a raíz de la derrota bélica. Si bien esta propuesta no fue del todo desarrollada por el autor mencionado, el tramo temporal que establece no resulta inviable. Adopto esta delimitación cronológica en la configuración del narrador "El Tunante".

4 Además de su brevedad, del objetivo generalmente pedagógico y de una permanente cuota de humor, el artículo de costumbres presenta algunas cualidades que lo convierten en una especie textual particular. El artículo de costumbres es un híbrido de recursos de literatura, historia y periodismo. Los elementos inventados en una estructura pautada se mezclan con sucesos cotidianos de la realidad y su composición está condicionada por la inmediatez del circuito periodístico donde se le publicaba diariamente. Esta es una premisa importante para la lectura y análisis del artículo de costumbres. Para ver más detalles sobre definición y características del artículo de costumbres, puede revisarse el prólogo en Antología costumbrista de Enrique Rubio Cremades y El cuadro de costumbres en el Perú decimonónico de Maida Watson.

5 Sobre la base de los recuerdos que Gamarra comparte en algunos de sus artículos de costumbres en los periódicos El Nacional y la Integridad, 
Su infancia transcurrió en ese distrito, dentro de una familia amorosa, distinguida en el pueblo y de cierta holgura económica. Sus padres, Manuel Guillermo Gamarra y Jacoba Rondo Quesada, poseían una de las fortunas más considerables del departamento de La Libertad (Basadre 1974: 18). En sus doce primeros años de existencia, Abelardo recibió lecciones vitales del padre sobre el valor del trabajo en el campo, el respeto a los peones y el aprecio los indígenas, y desarrolló su sensibilidad hacia las costumbres de las comunidades aborígenes. Basadre señala:

A los nueve años, por travesuras cometidas en el colegio, fue llevado a la hacienda familiar para que trabajara con los indiecitos que arrojaban semillas siguiendo tras las yuntas o las guiaban con un palito para que el surco fuese derecho. Su padre le enseño siempre a querer a los aborígenes. No era extraño a ellos en el sentido racial. Fraternalmente unido a los chiquillos de la casa y a los del caserío, fue su compañero de juegos en las noches estrelladas de verano, mientras los mayores estaban ocupados en dirigir las faenas de la trilla de trigo. El peón recibía allí trato humano. El padre de Abelardo era en Huamachuco apoderado de las comunidades y el niño solía concurrir frecuentemente a los "acuerdos" y fueron para él inolvidables los jefes de "huarangas" con sus cuellos parados a guisa de golas de grandes caballeros de cortes europeas, el calzón de chicote, el grueso bordón de lloque, los bucles largos a uno y otro lado de la cara (Basadre 1974: 18).

A su vez, la instrucción primaria de Abelardo estuvo bajo la tutela del padre. Él le enseñó las primeras letras con la Biblia

Justo Fernández calcula que el año de nacimiento de Gamarra fue en 1852. Luis Alberto Sánchez afirma que el año de nacimiento es 1857. Para mayor detalle sobre la fecha aún inexacta del año de nacimiento de Gamarra, revisar el artículo de Aladino Carbajal. 
en la mano, y le hizo aprender fábulas y recitar romances de Villergas y quintillas de Fray Gerundio. Y fue en la biblioteca paterna donde leyó a los clásicos españoles y franceses (Basadre 1974: 18).

En 1865, Abelardo adolescente fue llevado a Lima por su padre para que continúe sus estudios en el colegio de varones Nuestra Señora de Guadalupe. Este viaje determinó su vida. Además de su desplazamiento físico, atravesó fronteras culturales que no pasarían inadvertidas para él. Sus recuerdos, sus costumbres, su sensibilidad tuvieron que encajar en una Lima explícitamente europea y europeizante. Durante su etapa escolar, murió su padre y con él, tal vez, el vínculo más fuerte con Huamachuco. Abelardo se quedó a radicar en Lima.

Al término de su escolaridad, inició estudios universitarios en letras y jurisprudencia. Desde 1870, empezó a publicar en algunos diarios limeños y progresivamente el periodismo fue su actividad principal. Hacia 1871, había cursado casi todos los años respectivos de la carrera, pero debió abandonarla "cuando había cambiado por completo su condición económica, pues se había vuelto muy pobre” (Basadre 1974: 19). Ese año ingresa a trabajar en la redacción de El Nacional, prestigioso diario limeño; desde ese momento, publicar en prensa se volvió su medio de subsistencia en Lima. ${ }^{6}$ Como

168 forastero enraizado en la capital, se afincó en un nuevo lugar y tiempo, animado por un proyecto de vida nueva (Bueno 2010: 159). ${ }^{7}$

6 Otro de los medios de prensa donde Gamarra publicó inicialmente fue El Correo del Perú (1873).

7 La condición del forastero, según señala Raúl Bueno, varía según la duración de tiempo como visitante. Un forastero casual puede disfrutar o no 
En 1875, empezó a publicar en su columna personal "Rasgos de pluma", como redactor principal en El Nacional, vínculo que mantendría por varios años. Con ello, además de asegurar un ingreso económico estable, obtuvo uno de los logros más importantes para todo escritor. Con "Rasgos de pluma”, Gamarra inscribía su nombre en el circuito de periodistas literatos en Lima y obtenía un palco privilegiado desde el cual podía compartir opiniones en el espacio público y contar con el respaldo de un periódico de prestigio ${ }^{8}$.

En esta columna, el novel escritor se consolidó en el oficio de componer artículos de costumbres: aprendió la configuración de tipos y escenarios, los recursos para efectos de humor, y las dosis de crítica social y de didactismo para influir en la opinión de su lector. A su vez, mediante citas y reflexiones en sus artículos, Gamarra evidenció conocimiento sobre sus antecesores en Lima (Felipe Pardo, Manuel A. Segura, Ramón Rojas y Cañas, Manuel Atanasio Fuentes), así como sobre los íconos del costumbrismo español (José de Larra y Mesoneros Romanos). ${ }^{9}$ Aunque aún empleaba paralelamente

del viaje, pues solo está de paso. No necesita adaptarse al lugar que visita; su viaje no afecta su identidad. Incluso, puede experimentar con lo que observa en contraste con lo que él es, y así fortalecer su centro. En cambio, el forastero enraizado es objeto de situaciones más tensas; obligatoriamente, se enfrenta a adaptarse o vivir excluido en el nuevo lugar donde llega para quedarse, e intenta vivir o por lo menos sobrevivir en su nuevo "hogar". A su vez, puede ser visto por los lugareños como un invasor.

8 Sobre la importancia de la columna "Rasgos de pluma" en la formación del escritor, he publicado "Apuntes sobre la columna costumbrista 'Rasgos de Pluma' (1875-1880/1885-1889) de Abelardo Gamarra en El Nacional'.

9 Sobre el artículo de costumbres, revisar los textos ya sugeridos de Rubio Cremades y Watson. 
el seudónimo "El último haravec" en poemas y leyendas, en sus artículos de costumbres en "Rasgos de pluma" firmaba como "El Tunante", por lo que popularizó este seudónimo.

A un año de iniciada su columna "Rasgos de pluma", el joven Abelardo recibió el bautismo literario durante una de las célebres veladas en casa de la escritora Juana Manuela Gorriti, el 26 de setiembre de 1876. La madrina fue la novelista y ensayista Mercedes Cabello de Carbonera; el padrino, el poeta Manuel Adolfo García; el párroco, el tradicionista Ricardo Palma; el sacristán, el poeta Acisclo Villarán; y la nodriza, la poeta Manuela Villarán de Plascencia. Gamarra leyó su leyenda "La flor de Misquichilca", como expresión de su interés por costumbres nacionales. Este rito de pasaje para Abelardo Gamarra significó aceptación y respaldo de los cenáculos letrados limeños. ${ }^{10}$

El trasfondo social e histórico de "El Tunante" como forastero serrano en la capital es el fenómeno de migración interna en el Perú acontecido en la segunda mitad del siglo XIX. ¿Qué ocasionó el desplazamiento de los sujetos serranos a la costa? Según refiere Flores Galindo, este desplazamiento masivo respondió a la necesidad de cubrir la demanda de servidumbre doméstica a partir de la eliminación de la esclavitud de los afroperuanos en 1854. Bajo esta premisa, Ragas agrega que el crecimiento demográfico en la sierra originó la

10 En Veladas literarias de Lima, se menciona a los participantes y se detalla el ritual. En el mismo libro, se agrega las reseñas periodísticas respectivas publicadas en El Nacional, El Comercio y La Opinión Nacional. En este último, se señala lo satisfecho que debe encontrarse el escritor por las "manifestaciones que anoche se le hicieron. Sin herir su modestia, podemos asegurarle que las tiene bien merecidas". (La Opinión Nacional 1876, citado en Gorriti 1892: 479). 
expulsión de grandes contingentes de población a la costa, que empalmó consecuentemente con su ingreso al mercado laboral capitalino:

Hacia 1860, asistimos a la conformación de un interesante mercado de servidores domésticos que compiten o desplazan en sus funciones a los antiguos esclavos. Como en la actualidad, estos servidores domésticos eran objeto de control y exclusiones por parte de sus empleadores. Si bien algunos lograban obtener ese trabajo de forma voluntaria, o por medio de algún establecimiento creado para servir de enlace entre la oferta y la demanda -la primera de estas agencias se crea en 1859-, otros no tenían tanta suerte (Ragas 2008: 23) ${ }^{11}$.

La presencia de los migrantes de la sierra originó reacciones entre los residentes. Lima vislumbraba su desarrollo en planes de modernización y requería del engrosamiento del mercado laboral. Sin embargo, para los limeños, los migrantes de la sierra eran considerados solo fuerza de trabajo utilizable. Fuera de ello, no eran vistos como sujetos de derecho; más aún su presencia era considerada una amenaza. Esta reacción se tradujo en menosprecio y burlas hacia los migrantes, y un malestar en los residentes: "existían voces que manifestaron su preocupación por la masiva llegada de provincianos a partir de la década de 1860, pues consideraban que le quitaban prestancia a la ciudad y que el número de personas que pe-

11 Este desplazamiento, como señala Ragas, fue voluntario o forzoso. Sobre esta última modalidad, Flores Galindo refiere la práctica de "encargar cholitos". Niños y jóvenes, en muchos casos quechuahablantes, eran apartados de sus familias para servir en las casas de grupos sociales pudientes. Esta práctica común en Lima retrata la sensibilidad de la capital respecto a la población del país. Uno de los primeros artículos de Gamarra, "Los cholitos" (1873), denuncia este abuso. 
dían limosna por las calles estaba aumentando" (Ragas 2008: 24). ${ }^{12}$

"El Tunante" concebido como narrador forastero serrano dialoga con este fenómeno. Si bien la presencia de Gamarra en Lima fue por voluntad personal, para la realización de estudios que contó con el apoyo familiar, es probable que le afectasen los prejuicios que se estaban gestando sobre los migrantes serranos, sobre la sierra y la vida del campo. La elección del seudónimo no es casual, como tampoco lo fue la sensibilidad que elige mostrar en sus observaciones sobre Lima y sus evocaciones sobre la sierra.

\section{El narrador tras el seudónimo "El Tunante" en "Rasgos de Pluma"}

El empleo del seudónimo fue común entre los escritores durante el siglo XIX, tal como lo hicieron otros costumbristas. Para el caso de nuestro país, algunos seudónimos empleados por escritores costumbristas fueron "El murciélago" (Manuel Atanasio Fuentes), "El Baron de Keef" (Federico Elguera) y "Balduque" (Federico Blume). En Hispanoamérica, referentes españoles muy influyentes fueron "El curioso parlante", seudónimo de Ramón de Mesonero Romanos; y "El

12 Sucedió, además, la "racialización de la geografía", que Cecilia Méndez advierte en ese contexto. La sierra se imaginó poblada por indígenas, quienes por su raza no podían acceder, o incluso entorpecían, el proceso modernizador. Se proyectó hacia la sierra el atraso, la barbarie, lo primitivo. El grupo hegemónico costeño afianzó su condición política y económica privilegiada aplicando este discurso hacia la población serrana. Asimismo, es interesante el hecho de que la dualidad "costa"-"sierra" haya calado tanto en el imaginario nacional, al punto que la propuesta de Pulgar Vidal de los pisos altitudinales no la ha podido desplazar. 
duende", "Fígaro", "El pobrecito hablador" y "Bachiller", todos ellos seudónimos del escritor Mariano José de Larra.

Más que encubrir el verdadero nombre del autor, se trataba de distinguirse de otros escritores. Esto no se realizaba por el recurso paratextual en sí mismo, sino "lo que importaba era la creación de un narrador, una figura que aparecía a lo largo de una serie de artículos, a veces con todo lujo de detalles físicos, a veces sencillamente como una voz reconocible para el público lector" (Espejo Saavedra 2007: 33). ${ }^{13}$

En ese sentido, en el artículo de costumbres, un seudónimo puede generar la creación de una entidad para realizar afirmaciones dentro del texto. El seudónimo otorga un lugar a un narrador reconocible por el lector y le orienta en el texto, establece una perspectiva particular sobre lo que presenta. Asimismo, como señala Espejo Saavedra, este narra-

13 Resulta interesante, como precedente al análisis del narrador costumbrista, la reflexión que realiza Miguel Muro en el artículo "Cuestiones de técnica narrativa en los artículos costumbristas de El Pobrecito hablador" (1990). Él reconoce la dificultad que representaba para los estudios literarios investigar el artículo costumbrista, debido a los múltiples aspectos que estos poseen, entre ellos la inmediatez de su difusión, la frecuencia del contacto entre autor real y lector virtual en el medio periodístico. Como solución, él introduce la posibilidad de analizar estrategias como el establecimiento de las normas de comunicación: "narrador", "pacto narrativo" y "lector virtual". En particular, sostiene que establecer un "narrador", generalmente narrador protagonista, era parte de la tradición periodística. Se relaciona a ello el empleo de diferentes seudónimos que encubre y desplaza al autor real, pacto que debe respetar el lector virtual. A pesar de este pacto, el medio periodístico favorece la intromisión del autor, haciendo tambalear la figura del narrador. Teóricamente es sencillo distinguir autor de narrador; pero no así en la práctica. Además si no está bien construido el narrador, este no soporta la tensión de expresarse del escritor. 
dor puede presentarse con descripción de detalles físicos, de personalidad o ser solo una voz. En cualquiera de los casos, el seudónimo tiende a ser síntesis de características de un narrador. Por ello, es necesario reparar en el seudónimo. ${ }^{14}$

Actualmente, por la palabra tunante se entiende "Pícaro, bribón, taimado" (Diccionario de la Lengua Española 2014). El seudónimo de Abelardo Gamarra puede ser entendido de esa manera por los lectores. Puede ser considerado un "pícaro" por el atrevimiento de cuestionar las costumbres, sin censura que le restrinja. Su humor le permite criticar duramente prácticas sociales características de la urbe y del campo, y mantener el interés del lector.

Si profundizamos un poco más en el vocablo tunante y desplegamos el campo semántico que evoca en el contexto del escritor, existe un sentido adicional relevante. Para la época de Gamarra, fines del XIX, en el Diccionario de la lengua castellana de 1884, se registra como primer sentido de la palabra "tunante": "Que tuna". En este mismo diccionario, para la palabra tunar, la primera definición es "Andar vagando en vida holgazana y libre, y de lugar en lugar". Como segunda acepción de tunante, se señala "Pícaro, bribón, taimado". En ediciones anteriores del Diccionario de 1817 y 1822, para "tunante" se señala: "El que tuna o anda vagando", y como

174 segunda acepción: "Astuto, taimado". Remontándonos aún más en el tiempo y en publicaciones, la primera edición del Diccionario al empezar el siglo XIX (1803) brinda como única

14 El seudónimo puede ser usado también de manera irónica. Espejo Saavedra señala que en el caso de Mariano José de Larra, el seudónimo "El pobrecito hablador" contenía a un narrador nada ingenuo; por el contrario era malicioso, usualmente malhumorado y con trazos de misantropía. 
acepción de "tunante" como "El que tuna o anda vagando". Gamarra debió tener alguna noción del sentido de $t u$ nar como recorrer espacios "de lugar en lugar", similar al tránsito de un forastero. No le fue indiferente remarcar este sentido en sus artículos. ${ }^{15}$

En "Picanterías, las fondas, los restaurantes y los hoteles" (El Nacional 1875), ${ }^{16}$ Gamarra emplea un epígrafe muy significativo, a partir del cual brinda luces sobre cómo "El Tunante" se imagina a sí mismo y cómo busca presentarse ante sus lectores:

Y así sin dar parte alguna de su intención, y sin que nadie le viese, una mañana, antes del día, (que era de los calurosos del mes de julio), se armó de todas sus armas, subió sobre su Rocinante, puesta su mal compuesta celada, en el brazo su adarga, tomó su lanza, y por la puerta falsa de un corral salió al campo con grandísimo contento y alborozo de ver con cuanta facilidad había dado principio a su buen deseo (Cervantes).

("Picanterías, las fondas, los restaurantes y los hoteles", El Nacional, 1875).

15 No descarto el sentido de picardía en "El Tunante". Otro sentido que también podría abordarse en este seudónimo es el del "Tuno", en relación con el espíritu del músico trovador, pues Gamarra fue además compositor de letrillas para marineras y huaynos, pero sería materia de otro estudio.

16 Este es el primer artículo de costumbres que Gamarra publica oficialmente al empezar su columna "Rasgos de pluma". Este es un artículo inédito que se encuentra solo en prensa, Gamarra no lo publicó en ninguna de sus antologías posteriores. He rescatado este artículo como parte de la investigación para la tesis de maestría que estoy elaborando. Los artículos seleccionados solo se encuentran en "Rasgos de pluma" en El Nacional. Retornar a esta columna y recuperar los textos es crucial para visibilizar a "El Tunante" narrador. 
Con este extracto del primer capítulo de Don Quijote de la Mancha empleado como epígrafe por Gamarra, se procura el parangón entre el narrador de "El Tunante" con el caballero andante, protagonista de la célebre novela española. Coincide además que este artículo de costumbres se publicó en julio, mes en el que el Quijote emprendió su primera salida. Establecida la semejanza, se entiende que para "El Tunante" es también el inicio de una aventura en nuevas tierras, sin dar aviso ni pedir consentimiento. "El Tunante" anhela una aventura heroica, pero se sugiere que, como en el Quijote, su viaje tiende a una empresa maltrecha. Puede inferirse que, tal cual pasó con el Quijote, sus expectativas no se concreten y quede solo en ilusión. También, es posible inferir que en la narración de "El Tunante", el humor predomine sobre las aventuras heroicas.

Además del paralelismo con el protagonista andante, es notorio que el novel Gamarra empleó este epígrafe para validarse ante otros escritores y ante la comunidad letrada que se identificaba con Europa. Gamarra expone su vínculo con la tradición cultural hispana, colocando como referente a Cervantes quien ya entonces era considerado un ícono letrado español. En el primer párrafo del cuerpo del artículo, se refuerza el motivo del epígrafe. "El Tunante" estaba en empresa: "No de otra manera salimos hoy a comenzar nuestros escritos sobre cosas de esta Capital, y ojalá que aunque ellos nada valgan en sí, como las fa-

176 sañas del ilustre manchego, puedan dar algún entretenimiento al desocupado lector" ("Picanterías, las fondas, los restaurantes y los hoteles", El Nacional, 1875. Mis cursivas). La misión de "El Tunante", en su "salida" a recorrer las calles de Lima, es registrar las costumbres en sus escritos para posible solaz del lector. Se señala además una promesa de más escritos, un hito que se proyecta hacia el futuro. $\mathrm{Y}$ se explicita que estos tendrán como tema principal "cosas de esta Capital". 
En "Picanterías, las fondas, los restaurantes y los hoteles", "El Tunante" realiza un recorrido por estos lugares en el orden planteado en el título. Se ilustra con descripciones y escenas los cuatro tipos de lugares, detalla en qué zonas se encuentran en Lima, cómo suele ser la atención respectiva, y quiénes son los comensales de acuerdo con su solvencia económica. Así, a las picanterías se les encuentra en "Malambó ó el Cercado, donde abundan", los dueños "se visten de sucio", quienes atienden son "cholos coronguinos" que confunden los pedidos, y donde los comensales "son gentes que bien podemos llamar pueblo". Las fonditas "se hallan diseminadas en toda la capital, aquí y allá", los dueños que a su vez atienden suelen ser eficaces chinos, y el público es "gente definida o indefinida". El restaurante es considerado entre la fonda y el hotel, "como si dijéramos la bourgeoise", "en ellos manducan los cocheros y otras gentes bullangeras y parlanchinas". Sobre los hoteles, de los que se dice que existen pocos y de esos pocos no se indica dónde se encuentran, el narrador traza el camino tan solo con un "vamos con la aristocracia". En contraste con los tres anteriores, los hoteles destacan por su limpieza, luminosidad y ostentación: en las vitrinas se exponen frutas y carnes; los dueños son europeos y quienes atienden se visten pulcramente; los comensales "son gente acomodada: comerciantes, dependientes, prosistas, unos que tienes cómo, y otros porque digan: come en el hotel tal".

Efectivamente, en este artículo, se anuncia un hito inicial para "El Tunante", el comienzo de la aventura con un objetivo, tal cual se tratase de narrar sobre Lima como el mundo por conquistar. En esta primera incursión oficial en Lima, "El Tunante" ha elegido como punto de partida espacios donde concluyen diferentes tipos de la ciudad, y en el que 
recoge el crisol limeño en su heterogeneidad. Más que un recuento de lugares donde comer, "El Tunante" analiza a la distribución de la ciudad y a los diferentes grupos sociales de la capital que interactúan en ellos. Su condición de forastero le permite observar con distancia; además cuenta con cierta libertad para transitar y relacionarse en los cuatro espacios de distintos grupos sociales.

Cabe aclarar que adoptar la perspectiva de forastero es parte de las estrategias del escritor costumbrista, pues le permite mostrar lo conocido como nuevo o poder criticar las costumbres ajenas con distancia objetiva. Por ejemplo, lo observamos en las obras teatrales de Felipe Pardo y Aliaga: el juicio y la censura vienen a cargo del personaje inglés. De la misma manera, se aprecia en los artículos de Federido Elguera, en los que el narrador "El Baron de Keef" es extranjero, un letrado occidental, de la aristocracia y que casualmente se encuentra en Lima. Las alusiones a sí mismo como extranjero o de "otra raza" no son pocas, las enfatiza constantemente como una forma de validar su censura ante el caos y los excesos limeños. ${ }^{17}$

Es decir, al optar por un narrador foráneo, Gamarra empleó un recurso conocido en el costumbrismo. Sin embargo, en su caso, no es un narrador europeo como hicieron los escritores mencionados, sino un forastero serrano, lo cual lo

17 Federico Elguera (Lima, 1860-1928). Según Juan Pedro Paz Soldán, Elguera emplearía el seudónimo "El Barón de Keef” desde que participó como redactor eventual en El Comercio, en 1894. Además de escritor, fue el primer alcalde de Lima al iniciar el siglo XX, entre 1900 y 1909. Adoptar la perspectiva del extranjero es incluso una estrategia para los escritores modernistas, así por ejemplo en "Cartas de una turista" (1905) de Enrique A. Carrillo. 
colocaba en una situación marginal en el grupo social predominante eurocentrista. Su apuesta es inusual; el único caso similar, cercano temporalmente y en sintonía con la revaloración de la sierra, es el de la escritora cusqueña Clorinda Matto con quien Gamarra mantuvo amistad cercana. ${ }^{18}$

\section{Lima la excesiva y la nostalgia por el hogar serrano}

Hacia 1875, cuando empezó a firmar como "El Tunante", Gamarra llevaba viviendo alrededor de diez años en Lima y su experiencia en la ciudad era medianamente nutrida. Sucede algo semejante con el narrador "El Tunante". En los artículos publicados entre 1875 y 1877, el narrador se desenvuelve aparentemente sin dificultad en Lima; conoce sus calles; y asiste a festividades, ceremonias religiosas, paseos, meriendas, enredos políticos y otros. Sin embargo, se sostiene en distinguirse como un forastero serrano. Dentro de esta elección, opta por dos emociones para ser expuestas: la suspicacia sobre la capital y, a la par, la nostalgia por el terruño. Abelardo Gamarra prioriza qué emociones representar para su narrador de manera que sea consistente, y qué imágenes delinear de Lima y de la sierra.

El artículo "Semana Santa en Lima” (El Nacional 1876) abre con una añoranza del narrador: "Entre todas las festividades religiosas ninguna más augusta y más hermosa que la Semana

18 Advierto que en lugar de influencia entre ambos escritores, es posible afirmar que existió confluencia de intereses. Miseres señala que la voz narrativa de Matto "siempre en tránsito entre dos o más espacios y culturas" se consolidó posteriormente a su establecimiento en Lima (18861895). Para conocer más sobre la condición de migrante serrana en la narrativa de Clorinda Matto, revisar los textos de Ana Peluffo y Francesca Denegri señalados en la bibliografía. 
Santa, como que encierra la tradición de todo lo más grande que tiene el Cristianismo". En contraste, el narrador sentencia la perversión de esta festividad en Lima. De acuerdo con la descripción de "El Tunante", los limeños viven este rito religioso como si una fiesta pagana se tratase. Imperan la vanidad y la ostentación, que contrastan con el espíritu de reflexión que supuestamente debe primar en dichas fechas.

¿Qué es la semana santa en Lima? Es una fiesta como otra cualquiera en la que si bien hay una parte reducida de personas piadosas que la celebran debidamente, el resto se ocupa en pasear y distraerse. [...]

Semana en que se peca más que en otra ninguna y que de santa no tiene más que el nombre.

Venga ahora a decirnos que mentira, y que el espíritu de religiosidad predomina en ella.

¡El espíritu de religiosidad! Mucho espíritu de religiosidad hay en recorrer templos por mirar y ser mirada, mucho espíritu de religiosidad hay en ese lujo excesivo que se ostenta, mucho espíritu de religiosidad hay en ir a las iglesias como se va a los teatros!

Que me claven en la frente el tal espiritu de religiosidad.

180

(“Semana Santa en Lima”, El Nacional, 1876).

La representación de estas "cosas de la capital" es parte de su labor, lo que no impide a "El Tunante" realizar una crítica severa. La frustración nace de su expectativa sobre la virtud de la Semana Santa en la capital, expectativa destruida al confrontarse con lo que observa: exceso, vanidad y lascivia. Maneja el recurso de la ironía para enfrentar a quienes nieguen su crítica ("Venga ahora a decirnos que mentira, y que el 
espíritu de religiosidad predominan en ella") y la exageración para generar humor en la recepción de su lector ("Que me claven en la frente el tal espíritu de religiosidad”). A su vez, es notorio que, como parte de su condición de foráneo, "El Tunante" no se siente parte de lo que ha descrito. Es precisamente este desapego a la capital, lo que le permite observar como externo. Es la libertad para comentar lo observado, tal cual hace un extranjero en un mundo ajeno.

En contraste con la Semana Santa de la capital, en el artículo "La Noche Buena en los países del interior" (El Nacional 1877), ${ }^{19}$ se describe la práctica del rito católico con suma devoción en los pueblos de la sierra. No es la primera vez que Gamarra designa como "países del interior" a las provincias, lo cual remarca en una sensación de distancia respecto a la capital. Destaca en este artículo el decoro de esta celebración, el valor cristiano y el recogimiento de las familias. Para contrarrestar lo subestimación que pueda originar su lector limeño, "El Tunante" afirma: "Pueden estas costumbres ser muy tontas, pero lo que nosotros sabemos es que ellas contribuyen a conservar la paz en el seno de las familias, en el candor en el seno de las familias, el candor en el alma de los jóvenes, la pureza en el corazón de los niños”.

"Hasta cerca del amanecer dura las reuniones en las que no circula la menor gota del alcohol", se afirma. Queda explícita que la costumbre de honrar la Noche Buena de los pueblos del interior es una ceremonia circunspecta contraria a la costumbre de la capital. De esta manera, "El Tunante" insiste en describir los detalles de esa celebración:

19 Este es un artículo inédito que se encuentra solo en prensa. Lo he rescatado para el análisis del narrador costumbrista. 
No decimos que no nos gustan los placeres de la juventud, en esta bulliciosa capital, que no nos haya gustado alguna vez tomar en la Noche Buena el buen tamal en compañía de algunas niñas, con el respectivo piscolabis para que no se asiente, y bailar hasta la hora de la misa de gallo, misa de mataperrada y peñiscones; pero cambiaríamos con mil amores todas las noches buenas de esta capital, por una sola de aquellas buenas noches [...].

¡Dulce recuerdos de otra edad, para nosotros ya no seréis más que recuerdos; no más aquella santa alegría de otros tiempos hará latir el corazón; [...]

("La Noche Buena en los países del interior", El Nacional, 1877. El resaltado es de mi autoría).

Se reafirma la superioridad de las costumbres de los pueblos de la serranía sobre la capital, superioridad que puede también considerarse parte de su idealización del pueblo natal. Se recurre además a la existencia real que se exige del narrador costumbrista: "El Tunante" vive en la "bulliciosa" Lima y refiere disfrutar de los "placeres" de la juventud limeña en la Noche Buena: con la compañía, la comida, el alcohol y el baile, incluida la misa que es una situación de palomilladas y lances amatorios.

Tal como la describe el narrador, la Noche Buena en Lima es una gozosa fiesta, más carnal que espiritual. En este artículo, "El Tunante" afirma que esta fiesta no le molesta, pero tampoco le colma. "El Tunante" no es un censor severo; se permite condescendencias. Sin embargo, irremediablemente el hogar está en otra parte: no es Lima. El hogar es el mundo serrano que repite como perdido y que está muy presente en los artículos. El deseo de recuperar una Noche Buena de su vida en provincia (en trueque todas las Noches Buenas de Lima) revela la nostalgia del pueblo de origen; es un vínculo 
con el pasado al que no puede volver ("Dulce recuerdos de otra edad, para nosotros ya no seréis más que recuerdos”).

En "De Lima a Río Blanco" (ElNacional 1876), ${ }^{20}$ el narrador se entusiasma por su viaje en tren a La Oroya. "El Tunante" describe a los viajeros y anécdotas del viaje. Por ejemplo, para el narrador algunos limeños exageran sobre el frío, puesto que ya en la estación central del tren muchos de ellos comentaban sobre una posible helada y se preparan con indumentaria acorde. Para "El Tunante", los limeños sobredimensionan sobre el clima serrano:

No es un frio para llevar capotes y vestidos de gebe, salvo que el dia de ayer hubiese sido un dia especial y que en los otros se les hubiese congelado la sangre a los palanganas que lo ponderaban.

\section{¡Helada! ¡helada!}

¿Que fuera si estos tíos sintieran el verdadero frio de la puna; aquel que emparama a las gentes y que parece hacer cesar la circulación de la sangre: aquel frio de nieve?

(“De Lima a Río Blanco”, El Nacional, 1876).

Sobre la actitud de estos limeños en su incursión a la sierra, "El Tunante" se burla de ellos. Desmerece además los malestares de los que dicen ser afectados por el "soroche". Intenta moderar sus críticas y acota "Pobrecitos, los perdona "El Tunante" porque no saben lo que palanganean". Con esta sentencia, "El Tunante" afirma su propio conocimiento.

20 Este artículo también se encuentra solo en prensa. Es parte de los artículos que he rescatado y que propongo para el análisis del narrador costumbrista. 
Entre las anécdotas que presenta sobre este viaje a la sierra, casi terminando el artículo, destaca un recuerdo sobre el lugar de nacimiento del narrador. Un espacio campestre al que "El Tunante" profesa explícita pertenencia:

A la vista de los cerros de Rio Blanco, [...] todo un mundo fenecido en la realidad, pero vivo siempre en la memoria se presentó a mis ojos.

Era el recuerdo de mi infancia y el del escondido rincón donde nací.

No fue en ningún pueblo, fue en un caserío donde mis padres tenían también parte.

$[\ldots]$

Al mirarlo de lejos más que real parece un cuadro ex profesamente trabajado.

Lo verde de la pampa que le sirve como de fondo lo coposo y lo sano del más pequeño de sus árboles, su río caudaloso que hacia un lado se desliza cristalino, una que otra casita pintada de blanco y con su tejado color rojo, sus cielos siempre azul: todo hace de aquel rincón de la tierra como un retacito de cielo

(“De Lima a Río Blanco”, El Nacional, 1876).

Para el narrador, el viaje a La Oroya se convierte en un viaje 184 al origen. Observando los cerros y el verdor del campo, revive el "escondido rincón" de la sierra donde nació. Enfatiza incluso que donde nació fue un caserío y no un pueblo, para aclarar que se trataba de un lugar pequeño, poco poblado y sobre todo de vida campestre. Esta aclaración hace que su origen lo aleje aún más de la urbana Lima y de los limeños con quienes comparte el viaje en el tren pero que son ajenos a su sensibilidad. La acumulación de adjetivos calificativos 
positivos en la descripción del escenario exalta la abundancia y la dulzura del hogar perdido.

A través de su nostalgia, enaltece la sierra invitando al lector a compartir una imagen entrañable del "retacito de cielo" perdido, espacio tal vez desconocido por muchos de sus lectores capitalinos como por los viajeros del tren a la Oroya. A su vez, aunque califique a Lima (y a los limeños) de vanidosa, ostentosa y bulliciosa en demasía, no deviene en el extremo del rechazo. Resulta relevante que no registre otras emociones posibles de un forastero, como por ejemplo el miedo, desconfianza o recelo.

\section{Apuntes de cierre}

Sobre la base de lo expuesto, sostengo que Abelardo Gamarra elabora con "El Tunante" un narrador forastero serrano y ello puede demostrarse con el análisis de elementos contextuales y textuales de sus artículos de costumbres publicados en los primeros años de su columna "Rasgos de pluma".

En relación con elementos contextuales, resulta pertinente acudir a algunos elementos biográficos y un hecho social de la época. Considerando que la relación entre escritor real y narrador costumbrista es una de las fibras de consistencia del artículo de costumbres, algunos datos biográficos de Abelardo Gamarra pueden ser empleados para clarificar cualidades del narrador costumbrista. A su vez, el narrador "El Tunante" se enmarca en el fenómeno de migración interna, de sierra a costa, desde mediados del siglo XIX. Es probable que Gamarra se viese afectado por los prejuicios que se estaban gestando sobre la sierra, y que ello influyese en sus artículos y en su apuesta por un narrador forastero serrano. Gamarra asumía un reto con este narrador. 
En relación a elementos textuales, destaca el seudónimo y las emociones que predominan en el narrador forastero. $\mathrm{Al}$ reflexionar sobre el seudónimo, profundizamos en una estructura que imprime su personalidad en los artículos costumbristas. La noción de "tunar" o "andar vagando en vida libre" se aproxima bastante bien al sentido que emplea Gamarra con su seudónimo. "El Tunante", en los márgenes en que se desplaza, es efectivamente un forastero serrano que habita en Lima y muchos de sus artículos presentan a esta ciudad como su escenario. Su recorrido en Lima es una aventura tal cual proyectó con el epígrafe cervantino de su primer artículo; y cumple el ofrecimiento de describir a tipos y escenas con detalle para entretenimiento de su lector.

"El Tunante" como forastero serrano expresa principalmente dos emociones: suspicacia y nostalgia. Lima era una ciudad ajena que "El Tunante" evalúa en sus artículos durante los años previos a la guerra. El narrador estudia las "cosas de la capital" a la que califica de vanidosa, ostentosa y bulliciosa. Sin embargo, esta suspicacia no es radical. Las aspiraciones y los altibajos en las costumbres de la capital son criticados pero no del todo censurados; "El Tunante" se permite disfrutar de sus excesos. De manera complementaria por su cualidad de migrante, "El Tunante" infiltra la imagen del mundo serrano al que se refiere con facilidad y cercanía afec-

186 tiva. El paraíso perdido está muy presente en sus textos. A través de su nostalgia, invita al lector a compartir una imagen entrañable e idealizada de la sierra. La evocación del lugar de origen se intensifica por la imposibilidad del retorno.

"El Tunante", como narrador forastero serrano, se presenta como una voz que desestabiliza la sobrevaloración de la capital y confronta indirectamente los prejuicios sobre la sierra. 
Se puede entrever que, además de una apuesta estética, es una apuesta política del escritor que se renegociaría después de la experiencia de la guerra del Pacífico. Asimismo, acotemos que "El Tunante" resulta un precedente interesante para la representación de migrantes serranos en la literatura peruana del siglo XX y podría replantear el panorama que hasta la fecha se ha asumido.

Recibido: 10 de mayo del 2017

Aprobado: 18 de agosto del 2017

\section{Bibliografía}

El Nacional 1875-1877

Diccionario de la lengua castellana compuesto por la Real Academia Espanola 1803

Diccionario de la lengua castellana por la Real Academia Española 1817, 1822, 1884

Diccionario de la lengua española 2014

BASADRE, Jorge

1974 "Abelardo Gamarra”. En GALARRETA, Julio. Homenaje a Abelardo Gamarra. Lima: s/n.

BUENO, Raúl

2010 Promesa y descontento de la modernidad. Lima: Universidad Ricardo Palma.

CARBAJAL, Aladino

2017 "Abelardo M. Gamarra: controversias sobre la fecha de su nacimiento". Guamachuco. Revista de historia y cultura. Lima, año 1, número 2, pp. 3-9.

CORNEJO POLAR, Jorge

2001 El Costumbrismo en el Perú. Lima: Ediciones COPÉ. 
CORNEJO POLAR, Antonio

1996 "Una heterogeneidad no dialéctica: sujeto y discurso migrantes en el Perú moderno". Revista Iberoamericana. Estados Unidos, volumen 62, números 176-177, julio-diciembre, pp. 837-844.

1981 La cultura nacional: problema y posibilidad. Lima: Lluvia editores.

1994 Escribir en el aire. Lima: Editorial Horizonte.

DENEGRI, Francesca

2004 El abanico y la cigarrera: la primera generación de mujeres ilustradas en el Perú 1860-1895. Lima: Instituto de Estudios Peruanos.

ELGUERA, Federico

1999 [1913] El barón de Keef. Lima: Ignacio Prado Pastor.

ESPEJO-SAAVEDRA, Ramón

2007 "La creación y evolución del narrador larriano". Decimonónica, volumen 4, número 2. Consulta: 20 de setiembre de 2017. www.decimononica.org/ VOL_4.2/Espejo-Saavedra_4.2.pdf

\section{FERNÁNDEZ, Justo}

1954 Abelardo Gamarra, "ElTunante", su viday obra. Cusco: s.n.

GALARRETA, Julio

1972 Abelardo Gamarra en la crítica literaria. Lima: UNFV.

GAMARRA, Abelardo

1875

"Picanterías, las fondas, los restaurantes y los hoteles". En: "Rasgos de Pluma". El Nacional. 13 de julio.

1876

"Semana Santa en Lima". En: "Rasgos de Pluma". El Nacional. 08 de abril.

"De Lima a Río Blanco". En: "Rasgos de Pluma". El Nacional. 14 de agosto. 
GORRITI, Juana Manuela

1892 Veladas literarias de Lima. 1876-1877. Tomo I. Veladas

I al X. Buenos Aires: Imprenta Europa.

MISERES, Vanesa

$[\mathrm{s} / \mathrm{f}]$

"Clorinda Matto de Turner: recorridos de una escritora y su mirada continental". Consulta:15 de marzo de 2017. <http://eladd.org/autoras-ilustres/clorinda-matto-de-turner $/>$

MONCLOA Y COVARRUBIAS, Manuel

1938 "Los bohemios de 1886". En Costumbristas y satíricos. De Terralla a Yerovi. Selección de Ventura García Calderón. París: Biblioteca de Cultura Peruana.

MURO MUNILLA, Miguel A.

$1990 \quad$ "Cuestiones de técnica narrativa en los artículos costumbristas de El Pobrecito hablador". Cuadernos de Investigación Filológica. Zaragoza, volumen 16, pp. 49-58.

PELUFFO, Ana

1998

"El poder de las lágrimas: sentimentalismo, género y nación en Aves sin nido de Clorinda Matto de Turner". En MORAÑA, Mabel (editora). Indigenismo hacia el fin del milenio. Homenaje a Antonio Cornejo-Polar. Pittsburgh: Biblioteca de América, pp. 119-38.

PODESTÁ, Guido A.

1998 "Abelardo Gamarra: La poética del forastero". En: Indigenismo hacia el fin del milenio. Homenaje a Antonio Cornejo Polar. Mabel Moraña (editora). Pittsburgh: Instituto de Literatura Iberoamericana.

RAGAS, José 2008 "Del desencuentro a la inserción. Los migrantes de Lima y su representación (1850-1980)". En Casa de citas. Revista de literatura, No 5, pp. 22-26. 
Abelardo Gamarra "El Tunante" y el narrador forastero ...

RUBIO CREMADES, Enrique y María de los Ángeles Ayala 1985 Antología costumbrista. Barcelona: Ed. El Albir.

SÁNCHEZ, Luis Alberto

1965 Literatura Peruana. Lima: Ediventas.

1974 Introducción crítica a la literatura peruana. Lima: Villanueva Editor.

TORRES ESPINOZA, Jannet

2017 "Apuntes sobre la columna costumbrista 'Rasgos de Pluma' (1875-1880/1885-1889) de Abelardo Gamarra en El Nacional'. Entre Caníbales. Revista Literaria Peruana. Lima, número 3. pp. 29-40.

WATSON, Maida

1980 El cuadro de costumbres en el Perú decimonónico. Lima: Pontificia Universidad Católica del Perú. 